\title{
Frictional Melanosis of Rubbing Thighs in Iraqi Patients
}

\author{
Khalifa E. Sharquie*, Adil A. Noaimi, Attaa A. Hajji \\ Department of Dermatology and Venereology, Baghdad Teaching Hospital, Baghdad, Iraq \\ Email: "ksharquie@ymail.com, adilnoaimi@yahoo.com, attaa.alhaji2@yahoo.com
}

Received 28 March 2014; revised 25 April 2014; accepted 26 May 2014

Copyright (C) 2014 by authors and Scientific Research Publishing Inc.

This work is licensed under the Creative Commons Attribution International License (CC BY). http://creativecommons.org/licenses/by/4.0/

(c) (i) Open Access

\section{Abstract}

Background: Frictional melanosis of rubbing inner thighs is a common problem among Iraqi females causing great psychological and cosmetic impact. It might simulate lifa disease but it is a different entity. It is unfortunately not reported in the medical literatures although commonly encountered in daily clinical practice. Objective: To evaluate the hyperpigmentation of inner aspects of thighs in Iraqi females as an isolated pigmentary problem. Patient and Methods: Sixty patients with frictional melanosis of rubbing thighs were seen in Department of Dermatology, Baghdad Teaching Hospital in this case descriptive, clinical and histopathological study, during the period from April 2011 to March 2012. Any associated skin problems were also noticed like folliculitis and boils at area of friction. Forty individuals were enrolled in the present work as the healthy control group. The pigmentation was assessed by clinical, Wood's light and histopathological examinations (H\&E and Fontana stains). Body mass index was obtained for all patients and obesity was graded according to WHO recommendations. Results: The ages of patients ranged between 19 - $52(32.86 \pm 7.65)$ years, with $59(98.3 \%)$ females and $1(1.6 \%)$ male. By Wood's light examination, accentuation in pigmentation was observed in $39(58 \%)$ patients, while $21(42 \%)$ of lesions showed no change. Body mass index was ranged from 23.3 - 43.6 (34.04 \pm 4.13$)$, history of vigorous rubbing of pigmented area with washing tool (lifa) was positive in $46(76.6 \%)$ patients. Skin biopsies in 10 patients showed pure dermal melanophages in 3 of biopsies with slight melanosis of basal layer of epidermis, while the other 7 biopsies showed mainly increase in basal melanin. There was a statistically significant association between obesity and the severity of pigmentation of the inner thighs. Forty control individuals ( 2 males and 38 females) were assessed, their ages ranged from 19 - 50 (31.72 \pm 6.40$)$ years. All females were within normal weight while males were overweight and BMI was ranged from $19.7-28.2(22.49 \pm 1.84)$. All control individuals showed no pigmentation of inner aspects of thighs. Conclusion: Frictional melanosis of rubbing thighs is considered a new entity which had been not reported before in the medical literatures. This is a disease of mostly

\footnotetext{
${ }^{*}$ Corresponding author.
}

How to cite this paper: Sharquie, K.E., Noaimi, A.A. and Hajji, A.A. (2014) Frictional Melanosis of Rubbing Thighs in Iraqi Patients. Journal of Cosmetics, Dermatological Sciences and Applications, 4, 203-211. 
young obese females and the effective therapy is weight reduction and possibly liposuction.

Keywords

Frictional Melanosis, Rubbing Thighs, Iraqi Patients

\section{Introduction}

Melanosis is a major health problem among people with dark complexion and is well demonstrated in a form of facial melanosis, which could be caused by melasma (epidermal and dermal), gazelle eyes like facial melanosis, frictional melanosis, post inflammatory hyperpigmentation especially following lichen planus [1].

Melanosis could be also seen in any part of the body like in lifa disease; described in Iraq by Sharquie, 1993, as a new distinctive condition that followed chronic rubbing and friction with a lifa as washing agent. The distribution of the rash is very characteristic as it is only located over bony prominences [2]. All patients are slim, and using a washing agent (lifa) vigorously during bathing. The lesions are macular, symmetrically distributed with a positive family history of the same problem in $10 \%$ of patients [2].

Sharquie, speculated that the mechanism of pigmentation is due to repeated damage to the basal cell layer as a result of squeezing of the epidermis between the underlying bone and the offending wash brush (lifa), that is why the main histopathological picture shows many melanophages in the papillary dermis [3] [4]. Wood's light examination confirms that the melanosis is mainly dermal [2] [4].

Lifa disease could be considered as a variant of macular amyliodosis, as it was found that amyloid deposits were detected in about $10 \%$ of the biopsied cases [2] plus the following features:

1) Macular amyloidosis is a common condition among Asian and Middle Eastern people, including Iraqis especially females [5]-[11].

2) The features of pigmentation are similar in both macular amyloidosis and lifa disease. Sometimes might be a combination of both of them in the same patient [12].

3) The histopathology of both conditions consists of dermal melanosis [5] [12] [13].

4) Amyloid deposition could be seen in both diseases but more commonly in macular amyloidosis. Even in the latter, the amyloid deposition might be so small that examination of repeated biopsies and multiple sections is necessary for its detection [12].

Similar pigmentation has been described following chronic rubbing or friction in Japan [8] [10] [13]-[19], India [9] [20] [21], Jordan [3], Italy [22] [23], Oman [24], Israel [25], and UK [26].

Friction is also might be suggested as important cause of melanosis in medial aspects of thighs, although acanthosis nigricans (AN) might attribute to pigmentation of thighs which is the only hyperpigmentary state that is connected to clinical or subclinical insulin resistance and obesity, but hyperpigmentation in this condition is attributed to hyperkeratosis rather than to a mild increase in melanin pigmentation [27]. On contrary, two Iraqi studies of acanthosis nigricans demonstrated basilar hypermelanosis and dermal melanophages [28] [29]. There are no studies in the medical literature related pigmentation of rubbing thighs although there is only single report that described frictional hyperpigmentation on the inner aspects of the thighs and under bra straps as cutaneous manifestations of obesity [30].

Also in post inflammatory hyperpigmentation, pigment might follow injuries like burns, friction [31] and also after recurrent bouts of intertrigo which is a common cutaneous manifestation of obesity [32].

Darkly pigmented individuals are particularly prone to developing this form of hypermelanosis and it is of a greater magnitude, and persists longer [31] [33].

All patients with pigmentary disorders of the skin should be completely undressed and examined fully under both visible and Wood's light [34]. The visual assessment remains one of the "gold standard" methods in the diagnosis and assessment of skin color [29]. Histopathological studies with Hematoxylline and Eosien and other special stains like Fontana masson can assess both presence of melanin and precise site of deposition whether epidermal, dermal or mixed [34].

So, the aim of the present study is to do full clinical and histopathological evaluation and to be differentiated from other frictional melanoses. 


\section{Patients and Methods}

This case descriptive clinical and histopathological study was carried out in Department of Dermatology and Venereology, Baghdad Teaching Hospital during the period between April 2011 to March 2012. Sixty patients with hypermelanosis of inner aspects of thighs were included in this study.

Patients with the following conditions were excluded from this study: pregnant females, patients with hyperpigmentation of other flexural areas, skin tags, patients with systemic diseases or using of systemic drugs which could be associated with hyperpigmentation (like oral contraceptive pills), and those with history of using topical treatment within the last 6 months before presentation. No patients with underling diabetes, hypertension or other important medical conditions were noted.

History regarding the following points: age, gender, job, types of usually wearied clothes, duration, associated symptoms and aggravating factors, history of dermatitis (intertrigo), history of rubbing of pigmented skin by any tool, parity, familial history of atopic dermatitis and similar problem (hyperpigmentation of inner aspects of thighs). Thorough clinical examination done, weight and BMI was obtained for all the patients and obesity was graded as in Table 1, type of skin according to Fitzpatrick's skin typing.

The pigmentation was assessed by clinical examination regarding exact site, pattern of pigmentation (rippled or confluent), extension of pigmentation away from the area of contact between the two thighs, and associated cutaneous problems (like folliculitis) wasn't mentioned by the patient as a complaint.

The pigmentation was graded as follows:

Grade I: Light brown.

Grade II: Dark brown.

Grade III: Bluish (nearly black).

Wood's light was used as an important tool to assess the depth of pigment whether epidermal, dermal or mixed.

Formal consent was taken from all patients after full explanation to the patient about the goal of the present work, nature of disease course and possible modality of treatment. Also, ethical approval was performed by the Scientific Council of Dermatology \& Venereology-Arab Board for Medical Specializations.

Photographs were taken for each patient using Sony Cyper-Shot 6.0 Mega pixels camera in the same place and under good illumination in order to reassess pigmentation.

Laboratory investigations were done for female patients including hormonal assays: follicular stimulating hormone (FSH), luteinizing hormone (LH), (LH/FSH ratio) and serum free testosterone, in addition to pelvic sonography as a confirmatory test of PCOS.

The following criteria were used to establish the diagnosis of PCOS: the Rotterdam ESHRE/ASRM-sponsored PCOS consensus workshop group [Revised 2003 criteria (2 out of 3)].

1) Oligo and/or anovulation.

2) Clinical and/or biochemical signs of hyperandrogenism.

3) Polycystic ovaries on U/S examination [presence of ten or more follicular cysts 2 - 8 mm in one plane dis-

Table 1. Showing the degree of pigmentation in relation to degree of obesity in patients with frictional melanosis of rubbing thighs.

\begin{tabular}{cccc}
\hline BMI & Normal weight $(18.5-24.9)$ & Over weight $(25-29.9)$ & Obese (over 30) \\
\hline Grade I (n) & 1 & 7 & 11 \\
$\%$ & $100 \%$ & $63.6 \%$ & $22.9 \%$ \\
Grade II (n) & - & 3 & 14 \\
$\%$ & - & $27.2 \%$ & $23.16 \%$ \\
Grade III (n) & - & 1 & $47.9 \%$ \\
\hline
\end{tabular}

$\mathrm{P}$ value $=0.03$. 
tributed evenly around the ovarian periphery in a chain like manner (pearl/necklace) with an echo dense ovarian stroma, the ovaries are either normal or enlarged in size].

Incisional skin biopsies were carried out for 10 patients for H\&E and Fontana Masson staining (special staining for melanin) was done in order to determine all histopathological features of this disease.

Cosmetic impact assessment was also done according to the patients' awareness of their thighs pigmentation, as some patients feel it as an important cosmetic component causing disabling feature, while others were not interested. Forty apparently healthy individuals were enrolled in the present work as a control group (as patients complaining of other diseases mostly skin infections or companions of patients).

\section{Results}

Sixty patients with hypermelanosis of inner aspects of thighs, 59 (98.3\%) females and 1 (1.6\%) male, were included in this study. The age of the patients ranged between 19 - 52 years with a mean \pm SD of $32.86 \pm 7.65$ years, 59 female patients with a mean \pm SD of $32.91 \pm 7.75$ years; the duration of hypermelanosis ranged between 2 - 20 years with mean \pm SD of $6.4 \pm 3.58$ years.

Three (5\%) patients were unmarried, 19 (31\%) patients of females have one child, and all other females have more than one child. Fifty four females were housewives, one student, one driver, and 3 of them are office workers.

Twenty-four (40\%) patients using topical whitening commercial mixtures, while history of rubbing of pigmented skin by lifa (washing agent) was positive in 46 (76.7\%) patients.

History of bouts of intertrigo was positive in 52 (86.6\%) patients, especially during hot humid season. Four (6.6\%) patients were atopic, 3 of them had family history of atopy, in addition to 17 (28\%) patients had positive family history of atopy. Family history of hypermelanosis of inner aspects of thighs was positive in 46 (77\%) of cases.

According to Fitzpatrick’s skin typing: 38 (63.3\%) patients were skin type IV, 17 (28.3\%) patients were skin type III, 3 (5\%) patients were skin type V, and 2 patients (3.3\%) were skin type II.

Hypermelanotic areas have ill-defined borders confined to areas of maximum contact during walking in the medial sides of upper thighs; in 17 (28.3\%) patients, the pattern was rippled in 17(28.3\%) patients and confluent homogenous pigmentation was seen in the rest of patients (Figure 1).

BMI measurement show that all patients with frictional melanosis of inner thighs were obese except one and the patients were divided according to BMI into three groups: normal weight $1(1.7 \%)$, overweight $11(18.7 \%)$ and obese were 48 (18.4\%) patients, BMI was ranged from 23.3 to 43.6 with a mean \pm SD of $34.04 \pm 4.13$ (Table 1).

According to grading of pigmentation 19 (31.6\%) patients had Grade I pigmentation, 17 (28.3\%) had Grade II pigmentation and $24(40 \%)$ had Grade III pigmentation. Statistical analysis showed significant association between degree of obesity and severity of pigmentation $P$ value $\leq 0.03$ (Table 1, Figure 2).

No patient complained of itching of the rash but pseudofolliculitis confined to pigmented area was seen in 16 (26.6\%) patients, no itching was reported in all patients as a complaint. Bad odor from pigmented area noticed in

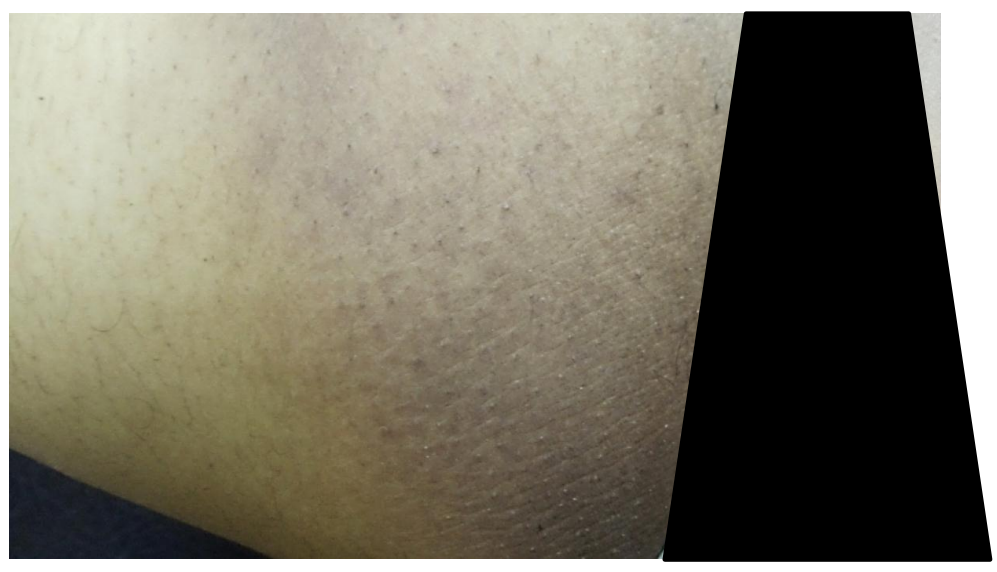

Figure 1. A twenty five years old married fertile female with dark brown (Grade 2) pigmentation on upper inner thighs BMI = 42.9. 


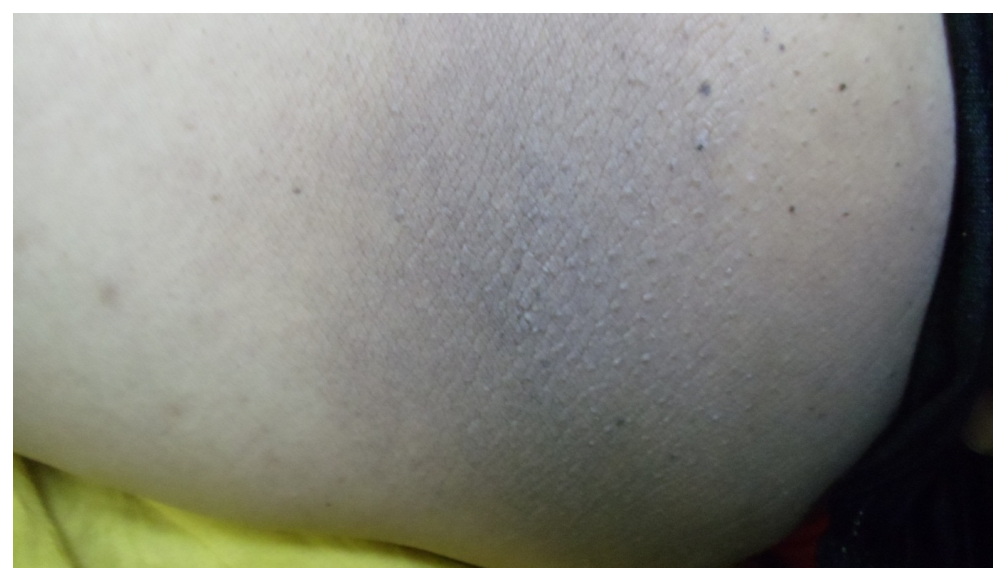

Figure 2. A thirty four years old married fertile female with bluish nearly black (Grade 3) pigmentation on upper inner thighs BMI = 36.4.

37 (61.6\%) patients.

Wood's light examination revealed accentuation in 39 (58\%) lesions which explained as epidermal or mixed (dermal and epidermal) pigmentation, while 21 (42\%) of lesions showed no accentuation which represented as dermal pigmentation. Pigmented skin was mildly thickened in comparison with normal non pigmented skin in 27 (45\%) of patients.

The cosmetic impact assessment had shown that 44 (73.3\%) patients were completely aware of this abnormal pigmentation, as two patients had been divorced because of this problem. At the same time some patients consider it normal familial condition as it is common in their sisters and mothers.

All 10 skin biopsies were obtained from patients with skin type IV. Histopathological examination revealed heterogeneous patterns of pigmentation as 3 of biopsies showed pure dermal melanophages spindle in shape (looks like fibroblast), while the other 7 biopsies showed mainly increase in basal melanin one of these revealed distribution of melanin all over the layers of epidermis although dermal melanophages had been observed in the last group but they were small and scattered (Figure 3, Figure 4).

Slight perivascular inflammatory infiltrate was observed in 3 (30\%) biopsies, no amyloid was seen observed in any of these biopsies (Table 2).

Two of female (3.4\%) patients fulfilled the criteria of PCOS, another 2 had history of PCOS, 3 (5\%) patients were postmenopausal.

Forty control individuals 2 males and 38 females were assessed, their age range from 19 to 50 years old with a mean \pm SD of $31.72 \pm 6.40$ years among 38 females same range with a mean \pm SD of $31.52 \pm 6.50$ years. Five (12.5\%) of them were atopic, while 10 (25\%) had family history of atopy.

All females were within normal weight, while males were overweight as BMI of them (28.2 and 26.9). BMI was ranged from 19.7 to 28.2 with a mean \pm SD of $22.49 \pm 1.84$, while among 38 females BMI was a mean \pm $\mathrm{SD}$ of $22.23 \pm 1.45$. No pigmentation of the inner thighs was noticed.

\section{Discussion}

Hypermelanosis is an important racial feature of black and dark skin individuals and has great psychological and emotional impacts on patients with such problems like melasma, Addison's disease, amyloidosis and its most common type macular amyloidosis, or could be seen as a part of frictional melanosis [4].

Lifa disease which is common among slim bony females with its predilection areas over bony prominences, is a common problem among Asians and Middle East countries especially in Iraq as Sharquie 1993 [2] [4] [29] [35] had reported and named this disease. Since then many other studies had been published in literatures [29].

Frictional melanosis is either induced by rubbing with washing tools like lifa, or by rubbing with hands, scratching [13], or as a result of abnormal counter of the body, like rubbing thighs in obese females.

Pathogenesis of lifa disease is thought to be as a result of squeezing of melanocytes in basal layer by washing agents like lifa against the underlying bony structures. This will cause damage of melanocytes and releasing of their melanosomes to the dermis, which will be seen as melanophages after engulfment by macrophages [4]. 


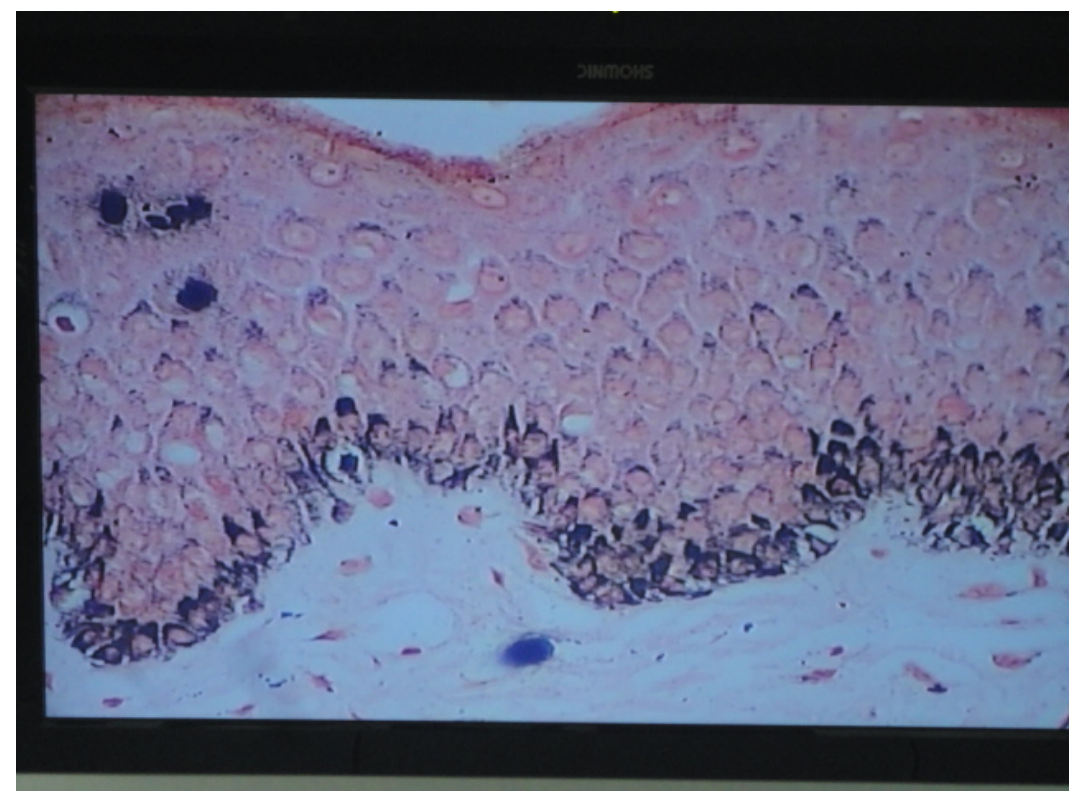

Figure 3. Fontana-Masson stained section showing basal hyperpigmentation and scattered melanophages in the dermis.

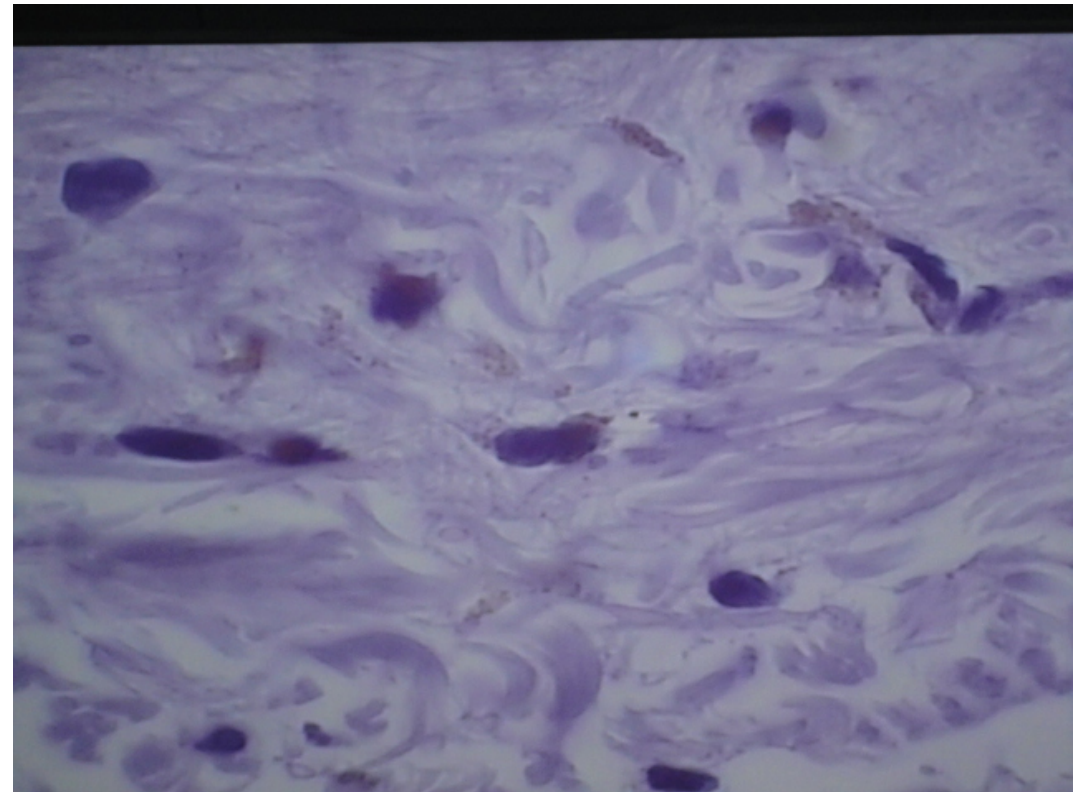

Figure 4. Hematoxylin-Eosin stained sections showing dermal melanophages.

Table 2. Showing the histopathological features of frictional melanosis of rubbing thighs.

\begin{tabular}{ccc}
\hline Feature & No. of patients & $\%$ \\
Mild hyperkeratosis & 10 & $100 \%$ \\
Mild acanthosis & 10 & $100 \%$ \\
Perivascular inflammatory infiltrate & 3 & $30 \%$ \\
Amyloid & 0 & $0 \%$ \\
By Fontana basilar hypermelanosis & 7 & $70 \%$ \\
By Fontana dermal melanophages & 3 & $3 \%$ \\
\hline
\end{tabular}


Table 3. Showing the comparison between FM of rubbing thighs and lifa disease.

\begin{tabular}{ll}
\multicolumn{1}{c}{ FM of rubbing thighs } & \multicolumn{1}{c}{ Lifa disease } \\
\hline Benign pigmentary problem resulted from frictional injury. & Benign pigmentary problem resulted from frictional injury. \\
Disease of young adult mostly females. & Disease of young adult mostly females. \\
$\begin{array}{l}\text { Disease of obese. } \\
\text { Friction between two folds of own skin. }\end{array}$ & Disease of slim. \\
$\begin{array}{l}\text { Pigmentation over fleshy parts. } \\
\text { Histopathologicaly Fontana stain showed that pigmentation could be } \\
\text { basilar or dermal without amyloid deposition. }\end{array}$ & $\begin{array}{l}\text { Pigmentation over bony prominences. } \\
\text { Histopathologicaly Fontana stain showed that pigmentation is } \\
\text { dermal with possible amyloid deposition. }\end{array}$ \\
\hline
\end{tabular}

Frictional melanosis of rubbing inner thighs is very common problem among Iraqi females causing great psychological and cosmetic impacts on many patients as this study shows (73\%), but unfortunately, this melanosis had not been reported in the medical literatures although commonly encountered in daily clinical practice (Sharquie 1990 personal observation). Accordingly the present study was arranged to report this new variety of FM and to the best of our knowledge, this is the first study to clarify this type of pigmentation clinically and histologically.

The present work showed that this variety of melanosis is mostly seen among obese females and the degree of pigmentation went parallel with the degree of obesity (Table 1).

Rarity of this condition among males may be related simply to the fact that it is totally cosmetic problem. Although it might be related more to anatomical differences in pelvis and gait between males and females [36], making rubbing of inner aspects of thighs nearly absent in males and even obese one as we reported 2 over weight males in the control group had no pigmentation of inner aspects of thighs (Table 3).

This type of hypermelanosis had the positive association with parity. After pregnancy the pigmentation in dark skinned females usually doesn't return to their normal skin color, especially when added to other factors like humidity, friction, using of commercial mixtures with unknown ingredients, and friction by other external agents in hope to decrease pigmentation.

According to this study it is not possible to regard this type of pigmentation as a type of atopic reaction as personal history of atopy was positive only in (6\%) of patients.

The pattern of pigmentation was dermal, epidermal or mixed as assessed by clinical, Wood's light and histological examination. This abnormal pigmentation is the main reason behind patients seeking medical therapy.

As this disease has great psychological and cosmetic impacts on these patients (73.3\%), accordingly therapy is mandatory needed.

History of vigorous use of washing agent (lifa) in an attempt to remove pigmentation was obtained in (76.7\%) of patients, which added to friction produced by rubbing inner thighs.

It is not surprising that only (3.4\%) patients had PCOS as we exclude cases of AN and skin tags at same area of friction (inner thighs) the most common cutaneous manifestations of insulin resistance which is the hallmark of PCOS [8] [37].

There are many options to clear this problem either weight reduction with or without giving topical emulsifying cream to minimize friction between rubbing thighs. If these therapeutic measures fail, we can suggest peeling using lactic acid [38] or liposuction as possibly mode of therapy.

\section{Disclosure}

This study was an independent study and not funded by any drug companies.

\section{References}

[1] Ruiz-Maldonado, R. and Orozco-Covarrubias, L. (2008) Metabolic and Systemic Diseases. In: Bolognia, J., Jorizzo, J. and Rapini, R.P., Eds., Dermatology, 2nd Edition, Elsevier, Spain, 672.

[2] Sharquie, K.E. (1993) Frictional Dermal Melanosis (Lifa Disease) over Bony Prominences. Journal of the Faculty Medicine (Baghdad), 35, 83-87.

[3] Al-Aboosi, M., Abalkhail, A., Kasim, O., Al-Khatib, A., Qarqaz, F. and Todd, D. (2004) Frictional Melanosis: A Clin- 
ical, Histologic, and Ultrastructural Study in Jordanian Patients. International Society of Dermatology, 43, 261-264. http://dx.doi.org/10.1111/j.1365-4632.2004.01606.x

[4] Sharquie, K.E. and Al-Dorky, M.K. (2001) Frictional Dermal Melanosis (Lifa Disease) over Bony Prominences. Journal of Dermatology, 28, 12-15.

[5] Wong, C.K. (1987) Cutaneous Amyloidosis. International Journal of Dermatology, 26, 273-277. http://dx.doi.org/10.1111/j.1365-4362.1987.tb00187.x

[6] Looi, L.M. (1991) Primary Localized Cutaneous Amyloidosis in Malaysians. Australasian Journal of Dermatology, 32, 39-44. http://dx.doi.org/10.1111/j.1440-0960.1991.tb00681.x

[7] Sharquie, K.E. and Hasson, S.M. (1991) Primary Cutaneous Amyloidosis in Iraqi Patients: Epidemiological, Clinical and Histopathological Study. Diploma Dissertation, University of Baghdad, Baghdad.

[8] Hidano, A., Mizuguchi, M. and Higaki, Y. (1984) Friction Melanosis. Annales de Dermatologie et de Vénéréologie, 111, 1063-1071.

[9] Sumitra, S. and Yesudian, P. (1993) Friction Amyloidosis: A Variant or an Etiological Factor in Amyloidosis Cutis. International Journal of Dermatology, 32, 422-423. http://dx.doi.org/10.1111/j.1365-4362.1993.tb02812.x

[10] Hashimato, K., Ito, K., Kumakiri, M. and Headington, J. (1987) Nylon Brush Macular Amyloidosis. Archives of Dermatology, 123, 633-637. http://dx.doi.org/10.1001/archderm.1987.01660290101025

[11] Tan, T. (1990) Epidemiology of Primary Cutaneous Amyloidosis in Southeast Asia. Clinics in Dermatology, 22, 10821087.

[12] Black, M.M. and Jones, E.W. (1971) Macular Amyloidosis: A Study of 21 Cases with Special Reference to the Role of the Epidermis in Its Histogenesis. British Journal of Dermatology, 84, 199-209. http://dx.doi.org/10.1111/j.1365-2133.1971.tb14208.x

[13] Wong, C.K. and Lin, C.S. (1988) Friction Amyloidosis. International Journal of Dermatology, 27, 302-307. http://dx.doi.org/10.1111/j.1365-4362.1988.tb02357.x

[14] Anekohji, K., Maeda, K. and Shigemoto, K. (1983) A Peculiar Pigmentation of the Skin over Bony Regions. Rinsho Dermatol (Japanese Journal of Clinical Dermatology), 25, 1259-1262.

[15] Asai, Y., Hamada, T., Suzuki, N., Nakano, K., Tanii, T. and Izutani, K. (1983) Acquired Hyperpigmentation Distributed on the Skin over Bones. Japanese Journal of Dermatology, 93, 405-414.

[16] Tanigaki, T., Hata, S., Kitano, Y., Nomura, M., Sano, S. and Endo, H. (1985) Unusual Pigmentation on the Skin over Trunk Bones and Extremities. Dermatologica, 170, 235-239. http://dx.doi.org/10.1159/000249539

[17] Tanigaki, T., Hata, S., Kitano, Y., Sano, S., Nomura, M. and Satoh, K. (1985) Epidemiological Survey of Nylon Clothes Friction Dermatosis. Nihon Hifuka Gakkai Zasshi, 95, 1159-1164.

[18] Iwasaki, K., Mihara, M., Nishiura, S. and Shimao, S. (1991) Biphasic Amyloidosis Arising from Friction Melanosis. The Journal of Dermatology, 18, 86-91.

[19] Hata, S., Tanigaki, T. and Misaki, K. (1987) Incidence of Frictional Melanosis in Young Japanese Women Induced by Using Nylon Towels and Brushes. The Journal of Dermatology, 14, 437-439.

[20] Somani, V.K., Shailaja, H., Sita, V. and Fatima, R. (1995) Nylon Friction Dermatitis: A Distinct Subset of Macular Amyloidosis. Indian Journal of Dermatology, Venereology and Leprology, 61, 145-147.

[21] Probhakara, V.G., Chandra, S. and Krupa, D.S. (1997) Frictional Pigmentary Dermatoses: A Clinical and Histopathological Study of 27 Cases. Indian Journal of Dermatology, Venereology and Leprology, 63, 99-100.

[22] Siragusa, M., Cavallari, V. and Schepis, C. (2000) Macular Amyloidosis Due to Friction by a Horsehair Glove. Dermatology, 200, 82-83. http://dx.doi.org/10.1159/000018327

[23] Siragusa, M., Ferri, R., Cavallari, V. and Schepis, C. (2001) Friction Melanosis, Friction Amyloidosis, Macular Amyloidosis, Towel Melanosis: Many Names for the Same Clinical Entity. European Journal of Dermatology, 11, 545-548.

[24] Venkataram, M.N., Bhushnurmath, S.R., Muirhead, D.E. and Al-Suwaid, A.R. (2001) Frictional Amyloidosis: A Study of 10 Cases. Australasian Journal of Dermatology, 42, 176-179. http://dx.doi.org/10.1046/j.1440-0960.2001.00514.X

[25] Naimer, S.A., Trattner, A., Biton, A., Avinoach, I. and Vardy, D. (2000) Davener’s Dermatosis: A Variant of Friction Hypermelanosis. Journal of the American Academy of Dermatology, 42, 442-445. http://dx.doi.org/10.1016/S0190-9622(00)90216-0

[26] Macsween, R.M. and Salhan, E.M. (1997) Nylon Cloth Macular Amyloidosis. Clinical and Experimental Dermatology, 22, 28-31. http://dx.doi.org/10.1046/j.1365-2230.1997.1770598.x

[27] Higgins, S.P., Freemark, M. and Prose, N.S. (2008) Acanthosis Nigricans: A Practical Approach to Evaluation and Management. Dermatology Online Journal, 14, 2.

[28] Sharquie, K.E., Al-Bayatti, A.A., Al-Zaidi, Q.M. and Al-Bahar, A.J. (2004) Acanthosis Nigricans as Skin Manifesta- 
tion of Polycystic Ovarian Syndrome in Primary Infertile Female. Middle East Fertility Society Journal, 9, 136-139.

[29] Sharquie, K.E., Noaimi, A.A. and Muhammad Ali, A.H. (2008) Acanthosis Nigricans in Iraqi Patients Clinical, Histopathological and Theraputic Study. Thesis for Fellowship of Iraqi Board for Medical Specializations in Dermatology and Venereology.

[30] García-Hidalgo, L., Orozco-Topete, R., Gonzalez-Barranco, J., Villa, A.R., Dalman, J.J. and Ortiz-Pedroza, G. (1999) Dermatoses in 165 Obese Adults. Obesity Research, 7, 299-302.

[31] Chang, M.W. (2008) Disorders of Hyperpigmentation. In: Bolognia, J., Jorizzo, J. and Rapini, R.P., Eds., Dermatology, 2nd Edition, Elsevier, Spain, 946-948.

[32] Bunker, C.B. and Neill, S.M. (2010) The Genital, Perianal and Umbilical Regions. In: Burns, T., Breathnach, S., Cox, N. and Griffiths, C., Eds., Chap. 71. Rook's Text Book of Dermatology, 8th Edition, Blackwell Scientific Publication, Singapore City, 4-6.

[33] Costin, G.-E. and Hearing, V.J. (2007) Human Skin Pigmentation: Melanocytes Modulate Skin Color in Response to Stress. The FASEB Journal, 21, 976-994. http://dx.doi.org/10.1096/fj.06-6649rev

[34] Ortonne, J.P. and Nordlund, J.J. (2006) Mechanisms That Cause Abnormal Skin Color. In: Nordlund, J.J., Boissy, R.E., Hearing, V.J., King, R.A., Oetting, W.S. and Ortonne, J.P., Eds., Chap. 28. The Pigmentary System: Physiology and Pathophysiology, 2nd Edition, Blackwell Scientific Publication, New York, 521-535.

[35] Sharquie, K.E., Al-Rawi, J.R. and Al-Tamimi, F.F. (2005) The Frequency of Skin Disease in Obese Children and Adult Iraqi Population. Saudi Medical Journal, 26, 1835-1836.

[36] Cho, S.H., Park, J.M. and Kwon, O.Y. (2004) Gender Differences in Three Dimensional Gait Analysis Data from 98 Healthy Korean Adults. Clinical Biomechanics, 19, 145-152. http://dx.doi.org/10.1016/j.clinbiomech.2003.10.003

[37] Sharquie, K.E., Bayatti, A.A., Ajeel, A.I., Bahar, A.J. and Noaimi, A.A. (2007) Free Testosterone, Luteinizing Hormone/Follicle Stimulating Hormone Ratio and Pelvic Sonography in Relation to Skin Manifestations in Patients with Poly Cystic Ovary Syndrome. Saudi Medical Journal, 28, 1039-1043.

[38] Sharquie, K.E., Al-Dhalimi, M.A., Noaimi, A.A. and Al-Sultany, H.A. (2012) Lactic Acid as a New Therapeutic Peeling Agent in the Treatment of Lifa Disease (Frictional Dermal Melanosis). Indian Journal of Dermatology, 57, 444448. 